\title{
Os Entre-Lugares na Relação Brasil-Japão: Migrações, Performances e Deslocamentos ${ }^{1}$
}

\section{The In-Between Places in the Brazil-Japan Relationship: Migrations, Performances and Displacements}

\section{Isis Caroline Nagami}

Universidade Estadual Paulista, Araraquara, São Paulo, Brasil

\section{RESUMO}

A partir da perspectiva dos estudos de performance, considerando o corpo como local de mediação das experiências, do individual ao coletivo, nos propomos a percorrer as multiplicidades de experiências incorporadas relacionadas à cultura japonesa no Brasil. Através dos conflitos sobre a representação de uma família japonesa e sobre os otakus e cosplayers em duas novelas brasileiras, e da atuação de coletivos de descendentes de asiáticos no Brasil, surgiram questões sobre estereótipos, fetiche, racismo, o mito da minoria modelo e sobre o lugar dos japoneses no processo imigratório pautado na ideia das três raças. Neste processo, conexões entre conhecimento incorporado, memória e história nos auxiliam a entender que as misturas raciais e culturais presentes nos imaginários sociais naAmérica Latina, carregam também histórias de transmissão cultural.

Palavras-chave: Migração, Performance, Entre-lugar.

1 O presente trabalho foi realizado com o apoio da Coordenação de Aperfeiçoamento de Pessoal de Nível Superior - Brasil (CAPES) - Código de Financiamento 001. 


\section{ABSTRACT}

From the perspective of performance studies, considering the body as a place for mediating experiences, from individual to collective, we propose to cover the multiplicity of incorporated experiences related to Japanese culture in Brazil. Through conflicts over the representation of a Japanese family and over otaku and cosplayers in two Brazilian soap operas, and the performance of collectives of Asian descendants in Brazil, questions arose about stereotypes, fetish, racism, the myth of the model minority and about the place of the Japanese in the immigration process based on the idea of the three races. In this process, connections between embodied knowledge, memory and history, help us to understand that the racial and cultural mixtures present in the social imaginary in Latin America, also carry stories of cultural transmission.

Keywords: Migration, Performance, In-between place.

\section{INTRODUÇão}

No Brasil, entre meados de 2016 a 2018, surgiram coletivos de descendentes de japoneses, chineses e coreanos que, através de canais no YouTube, páginas no Facebook e na internet, fizeram um movimento nos meios de comunicação de massa para levantar questões como: minoria modelo, fetiche, sexualidade, racismo, estereótipos e reconhecimento. Nesse mesmo período, nos meios de comunicação no Japão, eclodiam debates sobre a diversificação da sociedade contemporânea japonesa, o recente reconhecimento jurídico dos Ainu como população indígena, as mobilizações civis em busca de reconhecimento legal para casamento entre pessoas do mesmo sexo, a necessidade de ampliação das políticas públicas para dar estrutura às mulheres no que diz respeito ao trabalho e à maternidade, as demandas por flexibilização nas leis de imigração para a quarta geração de descendentes de japoneses do Brasil, e o reconhecimento dos hafu (mestiços), como parte da sociedade japonesa.

Em 2017, quando conectei essas experiências diversas, estava no Japão como decasségui pela segunda vez. Na primeira, antes da graduação em Ciências Sociais, percebi o choque entre "ser japonesa no Brasil" e "ser brasileira no Japão". Na segunda, talvez pela proximidade com a vida cosmopolita de Tóquio ou pela eficiente incorporação das experiências anteriores, meu olhar se voltou para as fissuras que permeiam essa ideia de "ser". Peirano (2014, p. 378) observa que "[...] tudo que nos surpreende, que nos intriga, tudo que estranhamos nos leva a refletir e a imediatamente nos conectar com outras situações semelhantes que conhecemos ou 
vivemos (ou mesmo opostas), e a nos alertar para o fato de que muitas vezes a vida repete a teoria". Neste artigo, através de algumas idas e vindas, nos propomos a considerar as multiplicidades de experiências incorporadas relacionadas à cultura japonesa no Brasil. Neste processo, memórias são rearticuladas e relacionadas a experiências que encontram no corpo o local de mediação.

\section{ENTRE IDAS E VINDAS: MIGRACÕES, PERFORMANCES E DESLOCAMENTOS}

Ao longo de mais de 110 anos de imigração japonesa no Brasil, as conexões entre os dois países têm se mantido e modificado. Entre idas e vindas de pessoas, artefatos e conhecimentos, as relações Brasil-Japão oscilam entre a percepção da manutenção da tradição e memória, e a integração das mudanças. Em janeiro de 2018, uma reportagem da BBC Brasil feita por Leticia Mori, observava que, para conhecer a língua tradicional de Okinawa, era necessário vir para o Brasil. Com um breve relato sobre a anexação do território de Okinawa pelo Japão no século XIX, observando-se a repressão do governo sobre a cultura local na época. A reportagem enfatizou as "raízes espalhadas" da imigração japonesa, sua diversidade cultural, e o importante papel das Associações Japonesas no Brasil, como espaços de manutenção das tradições e intercâmbio cultural, através do constante trânsito de estudantes, pesquisadores e bolsas de estudos.

Inicialmente criadas para ajudar os imigrantes na adaptação ao país, entidades governamentais e não governamentais têm atuado como espaços de conexão entre o Brasil e o Japão. Entidades como o Japan International Cooperation Agency (JICA), o Japan External Trade Organization (JETRO), a Fundação Japão, a Sociedade Brasileira de Cultura Japonesa (Bunkyo) e as Associações das Províncias Japonesas (47 províncias) têm mantido um constante diálogo de saberes através do intercâmbio de estudantes e pesquisadores, e investido na manutenção e promoção da cultura japonesa por meio da realização de cursos de línguas, artes, dança, mangá, arquitetura, paisagismo, esportes, lutas marciais, palestras e eventos.

Para aqueles que cresceram longe desses espaços, as associações locais da comunidade estiveram muito presentes. Em meados da década de 1990, entre alguns eventos mais "tradicionais", como o undo-kai (gincanas esportivas), os jogos de gateboll e os almoços seguidos de karaokê de músicas enka, meu preferido era o Bon-Odori, festival de culto 
aos mortos. ${ }^{2}$ Cresci indo a esses eventos no Brasil, dançando as músicas, e acompanhando o ônibus da Associação Cultural e Esportiva Nipo-brasileira (Nipo), que a cada fim de semana partia para alguma cidade diferente. As obaasan e ojiisan sempre iam com quimonos e $h a p p i^{3}$ de suas respectivas cidades, de modo que era possível identificar as cidades pelas cores, estampas, e pelos nomes delas em katakana. Durante as danças, os mais velhos ficavam do lado externo dos círculos, enquanto os mais jovens, ao centro, podiam brincar com a mudança na velocidade de execução dos passos, assim como realizar algumas improvisações.

Os eventos que participava quando era criança, realizados pelos Nipo de várias cidades, de Santa Fé do Sul a São José do Rio Preto, no interior de São Paulo, estavam sempre cheios dos japoneses que vieram para o Brasil, como a geração dos meus avós que chegaram na década de 1930, aos descendentes e mestiços da $2^{\mathrm{a}}$ e $3^{\mathrm{a}}$ geração, e dos não descendentes. As observações das diferenças entre japoneses, mestiços e brasileiros entre a comunidade nipo-brasileira eram comuns. ${ }^{4}$ A ideia do sangue como "marcador de grau de descendência nipônica", como substância que carrega “determinados atributos japoneses” (HATUGAI, 2011, p.89) estiveram presentes ao longo das experiências vividas, não apenas nas relações entre os frequentadores da Nipo e a família, mas também com a comunidade envolvente. Quando chegava atrasada na escola, sempre ouvia que "japoneses são pontuais" e que, portanto, eu devia ser pontual. Em diversas situações, como parte da repreensão ou exaltação por certos comportamentos, sempre me lembravam sobre a minha "japonesidade".5

As teorias sobre a japonesidade (nihonjinron) definem o "ser japonês" a partir de noções de raça/sangue, cultura/língua e território (MATSUE, PEREIRA, 2017; SUGIMOTO, 1999). Nessa concepção, "ser racialmente japonês" implica não apenas o "sangue", mas também o

2 ENNES, M. Bon-Odori: fronteiras simbólicas, identidades e estratificação social. Teoria e Pesquisa, São Carlos, v.19, n.1, p. 195-211, 2010.

3 O happi é um tipo de jaqueta feita em tecido simples que passou a ser usada por trabalhadores no Período Tokugawa (1603-1868) e é utilizada até os dias atuais. De acordo com Cristiane A.Sato (2007), o happi é a versão simplificada do haori, cujas mangas eram maiores, com a gola feita de seda e com o símbolos da atividade profissional ou kamon (insígnia da família).

4 Hatugai (2015, p. 3-4) observa que "[...] ser uma descendente mestiça sempre servia como ponto de reflexão para os sujeitos me explicarem as noções de ser japonês, ou a sua japonesidade, e as diferenças entre esses japoneses, os mestiços e os brasileiros". No entanto, diversas pesquisas recentes apresentam a heterogeneidade das múltiplas japonesidades entre os nipo-descendentes, os membros de grupos de prática de artes marciais, em relação à alimentação, como no caso do soba de Campo Grande e entre os grupos relacionados à cultura pop japonesa.

5 Tsuda (2003) utiliza a categoria "japaneseness" (japonesidade) para definir uma consciência étnica compartilhada entre os descendentes de japoneses que seria aprendida através da família e da comunidade étnica e os diferenciariam dos demais brasileiros. Tal perspectiva é criticada por autores como Silva (2008), Lourenção (2009), Machado (2011a), Hatugai (2011) que apontam a homogeneização e a circunscrição étnica da noção de japonesidade. 
domínio da língua e de determinados tipos de comportamentos. Quando cheguei ao Japão pela primeira vez percebi minha inadequação por ser "racialmente japonesa", mas não dominar a língua, o comportamento e a conduta ideal japonesa. ${ }^{6}$ Conheci nas falas de outros brasileiros com quem convivi, as diferenciações feitas entre os modos brasileiro e japonês de andar, de comer, de falar, de rir e de trabalhar. Salvo algumas semelhanças ou "japonesidades” observadas como "bem ensinadas" no seio da família, senti o constante desconforto de adequar meu corpo às técnicas corporais ${ }^{7}$ mais apropriadas ao contexto em que estava.

$\mathrm{Na}$ fábrica, o corpo era ajustado com as máquinas, com a metodologia de trabalho "5 S"8 (utilização, organização, limpeza, padronização, disciplina) e o relógio. Minutos, segundos e quantidade produzida. Era separado por idade, gênero e diferenças salariais entre mulheres e homens que às vezes executavam a mesma atividade, às vezes não (RONCATO, 2019). No começo, um corpo desajeitado, após um tempo, eficiente e produtivo. Na maior parte das vezes, dispensável e sujeito às oscilações de necessidade de mão de obra e demanda de produção, o que levava à mudança de local de trabalho e ao aprendizado de outra parte de algum processo de produção. Nessa época, não pensava nas técnicas do corpo, suas divisões e variações por sexos, idades, rendimentos e transmissão das formas técnicas, mas sentia cotidianamente os conflitos nas variações nos modos de caminhar, dormir, sentar e comer ${ }^{9}$, tanto na comparação entre o Brasil e o Japão quanto às diferentes regiões japonesas.

No início da graduação em Ciências Sociais, conheci o cosplay e a expressividade da prática no Brasil. Inicialmente, por influência dos debates no grupo de pesquisa em antropologia da performance, drama, estética e ritual, me dediquei à leitura de estudos realizados por autores como Victor Turner, Richard Schechner, John Dawsey e Regina Müller, e à reflexão da prática de cosplay como performance (NAGAMI, 2010; 2016). Através do uso metafórico da noção de liminaridade utilizada por Van Gennep (1960) para estudar os ritos de passagem em sociedades "primitivas", Turner (2012) propõe que essa noção pode ser utilizada para analisar a ação simbólica em sociedades complexas. Turner (2012) observa que, na fase liminal, os

6 Tsuda (2003), Linger (2001) e Matsue e Pereira (2017) apontam os conflitos e as novas configurações identitárias entre os brasileiros descendentes de japoneses através da experiência da migração.

7 Mauss (1935) e Foucault (1987).

8 Sistema de Controle Total de Qualidade baseado nas concepções de Seiri (utilização), Seiton (organização), Seisõ (limpeza), seiketsu (padronização) e shitsuke (disciplina).

9 Mauss (1935, p. 404) observa que “[...] Esses 'hábitos’ variam não simplesmente com os indivíduos e suas imitações, variam sobretudo com as sociedades, as educações, as conveniências e as modas, os prestígios. É preciso ver técnicas e a obra da razão prática, coletiva e individual, lá onde geralmente se vê apenas alma e suas faculdades de repetição". 
sujeitos rituais estão em uma situação indeterminada que permite que eles "brinquem" com elementos familiares e o desfamiliarizem, de modo que as novidades surgem das possibilidades de combinações dos elementos familiares. Nesse espaço liminar de estrutura normativa e "antiestrutura", pode-se observar "[...] o sistema latente das alternativas potenciais, as quais novamente irão surgir quando requeridas pelas contingências do sistema normativo" (TURNER, 2012, p. 223). Dawsey (2006, p. 18) observa que a grande

[...] sacada foi ver como as próprias sociedades sacaneiam-se a si mesmas, brincando com o perigo, e suscitando efeitos de paralisia em relação ao fluxo da vida cotidiana. Às margens, no límen, se produzem efeitos de estranhamento Desloca-se o lugar olhado e ouvido das coisas. Gera-se conhecimento.

Os estudos sobre performance moveram-se, durante os anos 80, de uma preocupação com o performer e o ato performático para a consideração da importância da plateia que participa da performance, quem a está reportando e as implicações políticas, sociais e cognitivas (CARLSON, 2010). Com o deslocamento das noções de observador neutro para um participante ativo da performance (tanto na experiência inicial quanto na retransmissão da experiência) adentramos o complexo campo da performance intercultural em que as performances, conectando-se com outras culturas e outras performances, tecem modelos complexos de contato (CARLSON, 2010; TAYLOR, 2013).

Com a finalização do mestrado e com as baixas expectativas de trabalho, decidi voltar para o Japão. À estranheza do deslocamento soma-se a ansiedade de retornar, após dez anos de partida. Durante a semana, trabalhava em uma fábrica de alimentos na cidade de Narashino, nas proximidades de Tóquio. Aos finais de semana, saía para praticar a fotografia em parques, lugares turísticos e em alguns eventos de mangá e cosplay. Desta vez, talvez pela proximidade com a multiplicidade de subjetividades em Tóquio ou pela eficiente incorporação da experiência anterior, a questão central que me diferenciava dos japoneses não era mais o comportamento ou conduta, mas a língua. O contato fora do trabalho com japoneses e outros estrangeiros no Japão (e às vezes com alguns brasileiros) geralmente era iniciado com a suposição de que eu era japonesa. Após a constatação negativa, sempre apareciam assuntos sobre migração, família, visto de moradia e de que no Brasil a língua é o português (diferente de Portugal) e não o espanhol.

Na história da migração japonesa, observa-se que a partir da década de 1860, o país enfrentava alta taxa de densidade demográfica e desemprego, e que a emigração foi uma solução encontrada pelo governo japonês (COTRIM, 2016; SAKURAI, 2000). Havaí, Estados Unidos, Peru e Brasil foram alguns dos países que receberam esses trabalhadores, entretanto, as expe- 
riências desses migrantes foram diferentes em cada contexto colonial. No Brasil, o governo exigia a entrada de famílias, no Peru não havia essa restrição, aceitando homens solteiros para trabalhar nas fazendas de açúcar (COTRIM, 2016; SAITO, 1958; SAITO, MAEYAMA, 1973). Enquanto na América Latina e no México, o predomínio do termo mestiço expressa a colonização dos corpos, nos Estados Unidos, a colonização foi construída pelas ideias de assimilação cultural do "ser americano".

No Brasil, a imigração se tornou uma opção de mão de obra após o fim da escravidão. Inicialmente, as políticas eugênicas favoreceram a entrada de trabalhadores da Alemanha, Portugal, Espanha e Itália. A ideia de um "embranquecimento" do país levou as elites da época a apoiarem a entrada desses migrantes. Após um tempo, iniciou-se o emprego de mão de obra não europeia, o que implicou em uma rearticulação da ideia de "brancura" como requisito para a inclusão na "raça brasileira". ${ }^{10}$ Lesser (2001, p.19) observa que, durante o século XX, os integrantes da elite imigrante "engajaram-se num discurso público sobre o que é ser brasileiro", criando gêneros orais e escritos que reformulavam as diferenças étnicas. Algumas elites imigrantes se posicionavam como grupo etnicamente "branco", outros enfatizavam as melhorias trazidas ao Brasil por se tornar mais "japonês" ou "árabe". Neste contexto, pensar a "mistura" de povos foi compreendido como uma "[...] união de diferentes identidades, com a criação de uma multiplicidade de brasileiros hifenizados (por exemplo, nipo-brasileiros, sírio-libaneses), e não um grupo único e uniforme” (LESSER, 2001, p. 22).

Durante a Segunda Guerra Mundial, a figura do "perigo amarelo" levou alguns países a adotarem práticas restritivas aos japoneses e seus descendentes. Takeuchi (2003, p. 2) observa que, nesse período no Brasil, os "nipônicos passaram a ser vigiados como suspeitos de sabotagem e espionagem" e a nipocidade tornou-se inadmissível sob a acusação de antinacionalismo e como "prova" de sua não assimilação e lealdade. Nos anos 60, com a mudança de posição econômica e política japonesa a nível mundial, popularizou-se a ideia de "minoria modelo". Em 1966, o sociólogo Willian Pettersen publicou uma matéria no New York Times em que ele enfatizava o sucesso dos japoneses nos negócios nos Estados Unidos. ${ }^{11}$ Ele observa que apesar do histórico desfavorável - de preconceito, exclusão racial e campos de concentração durante a Segunda Guerra Mundial - os japoneses americanos possuíam taxas de escolarização acima da

10 A Teoria do Triângulo sobre a sociedade brasileira propõe uma civilização criada a partir da colisão de três raças: africanos, brancos e indígenas. Muitos acadêmicos supuseram ou sugeriram que qualquer pessoa que não tivesse ascendência africana ou indígena se encaixaria na definição de branco.

11 PETTERSEN, W. Success story, Japanese-american style. New York Times, New York, 09 jan. 1966. Disponível em: https://www.nytimes.com/1966/01/09/archives/success-story-japaneseamerican-style-success-story-japaneseamerican.html. Acesso em: 10 jan. 2020. 
média, baixos índices de criminalidade e notável empreendedorismo. Pettersen constata que a "chave" para o sucesso dessa minoria étnica estaria na "[...] ética e valores culturais japoneses como colocar o bem comum acima do individual, respeito à autoridade, apego à ancestralidade e a força dos vínculos familiares" (NAKAMOTO, 2019, p. 30), qualidades ausentes entre "negros e mexicanos". Apesar das críticas, diversos intelectuais, políticos e organizações nipoamericanas utilizaram essas representações em eventos, publicações e memoriais.

No Brasil, essas representações foram amplamente utilizadas por empresas japonesas na década de 60, intensificando-se nos anos 70. Nesse período, com o intuito de colaborar com o Ministério das Relações Exteriores, criou-se o Instituto de Estudos Afro-Asiáticos (Ibeaa) em abril de 1961 que, com o Golpe Militar, teve suas atividades encerradas no ano de 1964. Na década de 1970, surgiu o Centro de Estudos Afro-Asiáticos (Ceaa), que abrangia os estudos africanistas, orientais e afro-brasileiros. Nessa mesma década, diversas universidades públicas passaram a oferecer cursos de extensão regulares de ensino da língua e cultura japonesa (PEREIRA, 2003).

Quadro I. Relação entre áreas de estudo e concentração de publicações por tema.

\begin{tabular}{|c|c|c|c|}
\hline & Estudos sobre o Japão & $\begin{array}{l}\text { Estudos sobre a comu- } \\
\text { nidade Nipo-brasileira }\end{array}$ & $\begin{array}{c}\text { Estudos sobre a relação } \\
\text { Brasil-Japão }\end{array}$ \\
\hline $\begin{array}{l}\text { Concentração } \\
\text { de publicações } \\
\text { por tema }\end{array}$ & $\begin{array}{l}\text { Predominância: Lin- } \\
\text { guística e Literatura. } \\
\text { Em menor escala: His- } \\
\text { tória, Política, Artes, Co- } \\
\text { municação, Arquitetura, } \\
\text { Religião, Antropologia, } \\
\text { Sociologia. } \\
\text { Recentemente: Econo- } \\
\text { mia, Comércio e Admi- } \\
\text { nistração. }\end{array}$ & $\begin{array}{l}\text { Estudos sistemáticos a } \\
\text { partir da década de } 1940 . \\
\text { Recentemente: Reli- } \\
\text { giosidade japonesa no } \\
\text { Brasil, Língua da colônia } \\
\text { japonesa no Brasil, Ensi- } \\
\text { no de japonês no Brasil. } \\
\text { Observação: os estudos } \\
\text { sobre os decasséguis } \\
\text { transitam pelas três cate- } \\
\text { gorias. }\end{array}$ & $\begin{array}{l}\text { Observação: ganharam } \\
\text { maior dimensão na década } \\
\text { de 1970, devido ao "mila- } \\
\text { gre econômico japonês" e } \\
\text { a ampliação das relações } \\
\text { entre os dois países. }\end{array}$ \\
\hline
\end{tabular}

Fonte: Elaborado pela autora com base em Pereira (2003).

Como podemos observar, os estudos linguísticos, as pesquisas sobre a comunidade nipo-brasileira e os estudos econômicos predominam nos centros de pesquisa e estudo no Brasil. Como vimos anteriormente, os Estudos Asiáticos e os Estudos Afro-brasileiros foram, em diversos momentos, colocados nos mesmos espaços de pesquisa. Pereira (2003) observa essa par- 
ticularidade histórica do processo de consolidação dos centros de estudos. Ele pontua a curiosa unificação dos estudos asiáticos com os africanos e a sua aparente conexão com o Movimento dos Países Não-Alinhados que, entre os anos 50 e 80, surgiu “[...] como uma reação dos países em desenvolvimento contra a diplomacia divisionista das superpotências no contexto da Guerra Fria” (PEREIRA, 2003, p.11). Na atualidade, diversos autores observam as influências das teorias sobre a "japonesidade" (nihonjinron) e, a partir de pesquisas com as experiências vividas com a cultura japonesa no Brasil, observam as multiplicidades de japonesidades possíveis e dissonantes.

Olhar para as dissonâncias como "japonesidades" instaura uma deshierarquização da análise: a japonesidade homossexual é tão inteira, importante quanto à japonesidade dos "descendentes" que criam as vidas associativas dos clubes nipo-brasileiros. [...] Temos ontologias e não fragmentos ou "subidentidades", "sub-culturas". A forma de ser "nipo-descendente" de um lutador de kendô não descendente (sem olhos puxados) é tão japonesa quanto a das velhinhas do Odori na associação Nipo em Araraquara. A japonesidade vista como múltipla permite que não analisemos as condições desses sujeitos como "menos ou mais" japonesas, mas como japonesas à sua maneira. Isso não quer dizer que não haja processos hegemônicos (os há) e que os próprios japoneses não se refiram a seus "co-étnicos" como mais ou menos japoneses. Eles o fazem muito frequentemente, e o fazem a partir de perspectivas referentes aos seus modos de ser japonês. (MACHADO, 2011b, p.15).

As mudanças e oscilações em relação às imagens dos japoneses e a sua japonesidade são observadas por Sugimoto (2014). O autor pontua que o impacto do olhar e o interesse sobre o Japão levou ao surgimento de diversos livros e artigos, tanto dentro quanto fora do Japão, que pretendiam identificar a essência dos japoneses. Os estudos sobre o Japão podem ser divididos em três fases, conforme apresentamos no Quadro II.

Quadro II. Fases dos estudos sobre o Japão e suas imagens.

\begin{tabular}{|c|c|c|c|}
\hline Critério comparativo & $\begin{array}{c}\text { Primeira fase (1950- } \\
\text { 1960) }\end{array}$ & $\begin{array}{c}\text { Segunda fase (1970- } \\
\text { 1980) }\end{array}$ & $\begin{array}{c}\text { Terceira fase (1990- } \\
\text { 2000) }\end{array}$ \\
\hline \multicolumn{3}{|c|}{ 1. Imagens populares no Exterior } \\
\hline $\begin{array}{c}\text { Imagens populares no } \\
\text { exterior }\end{array}$ & $\begin{array}{c}\text { Bushido, Judô, } \\
\text { Kabuki, Noh, cerimô- } \\
\text { nia do chá, gueixa }\end{array}$ & $\begin{array}{c}\text { Coletividade, empre- } \\
\text { go vitalício, sindicatos } \\
\text { empresariais, controle } \\
\text { de qualidade, Kanban } \\
\text { (sistema produtivo), bu- } \\
\text { rocracia }\end{array}$ & $\begin{array}{c}\text { Cool Japan, mangá, } \\
\text { anime, sushi, karaokê, } \\
\text { J-Pop, fashion, cu- } \\
\text { linária }\end{array}$ \\
\hline
\end{tabular}




\begin{tabular}{|c|c|c|c|}
\hline Atributos principais & $\begin{array}{l}\text { Inescrutável, miste- } \\
\text { rioso, extremamente } \\
\text { exótico }\end{array}$ & $\begin{array}{l}\text { Sério, paciente, diligente, } \\
\text { perseverante, consensual }\end{array}$ & $\begin{array}{l}\text { Brincalhões, hilários, } \\
\text { sexy, imprevisíveis, } \\
\text { divertidos }\end{array}$ \\
\hline $\begin{array}{l}\text { Maiores consumidores } \\
\text { das imagens }\end{array}$ & $\begin{array}{l}\text { Um pequeno número } \\
\text { de especialistas sobre } \\
\text { o Japão }\end{array}$ & $\begin{array}{l}\text { Empresários e funcioná- } \\
\text { rios do governo }\end{array}$ & $\begin{array}{l}\text { Jovens, urbanos, cama- } \\
\text { das populares }\end{array}$ \\
\hline \multicolumn{4}{|c|}{ 2. Paradigmas dos Estudos Japoneses } \\
\hline Neustupny (1980) & Japanologia & Estudos de Área & $\begin{array}{l}\text { Paradigma Contempo- } \\
\text { râneo }\end{array}$ \\
\hline Steinholff (2007) & $\begin{array}{l}\text { Língua e estudos de } \\
\text { área }\end{array}$ & Competição econômica & Estudos Culturais \\
\hline Chiavacci (2008) & Luta de classes & $\begin{array}{l}\text { Sociedade de classe mé- } \\
\text { dia }\end{array}$ & Divisão social \\
\hline Autores reconhecidos & Benedict; Maruyama & Nakane; Doi; Vogel & Befu; Oguma; Ishida \\
\hline Cultura & Monocultural & Monocultural & Multicultural \\
\hline Atributos chave & $\begin{array}{c}\text { Tradicional, passado, } \\
\text { obrigação }\end{array}$ & $\begin{array}{l}\text { Orientação coletiva de } \\
\text { grupo, sem classes, inte- } \\
\text { grativo }\end{array}$ & $\begin{array}{c}\text { Diferenciação de } \\
\text { classes, diversidade, } \\
\text { competitividade inter- } \\
\text {-étnica }\end{array}$ \\
\hline $\begin{array}{l}\text { Estudos japoneses em } \\
\text { relação ao sistema } \\
\text { mundial de conheci- } \\
\text { mento }\end{array}$ & $\begin{array}{l}\text { Critérios eurocêntri- } \\
\cos \end{array}$ & $\begin{array}{l}\text { Nihonjinron como relati- } \\
\text { vismo cultural }\end{array}$ & $\begin{array}{l}\text { Compõe parte dos } \\
\text { fluxos de ideias não } \\
\text { europeias }\end{array}$ \\
\hline \multicolumn{4}{|c|}{ 3. Condições superestruturais subjacentes } \\
\hline $\begin{array}{l}\text { Condições superestru- } \\
\text { turais subjacentes }\end{array}$ & $\begin{array}{c}\text { Sociedade agrária, } \\
\text { ocupação americana, } \\
\text { recuperando-se da } \\
\text { Segunda Guerra Mun- } \\
\text { dial }\end{array}$ & $\begin{array}{c}\text { Capitalismo industrial, } \\
\text { superávit comercial, bo- } \\
\text { lha econômica, integra- } \\
\text { ção vertical }\end{array}$ & $\begin{array}{l}\text { Capitalismo cultural, } \\
\text { globalização, migração } \\
\text { transnacional, enve- } \\
\text { lhecimento, deflação, } \\
\text { sociedade civil }\end{array}$ \\
\hline
\end{tabular}

Fonte: Elaborado pela autora com base em Sugimoto (2014).

Na primeira fase (1950-1960), a sociedade japonesa era vista como predominantemente agrária, com uma economia engajada no setor primário. Com o final da Segunda Guerra e a ocupação norte-americana, o país foi caracterizado como uma sociedade atrasada, semifeudal e autoritária que precisava absorver a democracia e o liberalismo ocidental. Após a Segunda Guerra Mundial, a cultura japonesa passou a ser percebida como uma cultura homogênea, singular e oposta à cultura ocidental, sendo então amplamente analisada a partir da noção de que 
haveria características distintivas da personalidade, da cultura e da sociedade japonesa. Com a expansão econômica nas décadas de 1970 e 1980, as chamadas literaturas nihonjinron (que nas décadas anteriores buscaram definir a "quintessência japonesa") desfrutaram do seu auge, “[...] quando escritores competiam entre si para apresentar o que consideravam serem as chaves para desvendar os segredos culturais do incrível desempenho econômico do Japão" (SUGIMOTO, 2014, p.92), além da ampla produção de textos acadêmicos, jornalísticos, romances e negócios, que buscavam destacar e glorificar aspectos da cultura japonesa, tais como perseverança, lealdade, polidez, hospitalidade e laboriosidade. Com a terceira fase (de 1990 a 2000), vemos a ascensão do cool Japan, com a imagem de uma nação tecnológica, estética e integrativa, e a associação da cultura japonesa com MASK (mangá, anime, sushi e karaokê). Sugimoto (2014) diz que tal mudança relaciona-se às transformações no setor manufatureiro do Japão que - com a perda de sua vantagem competitiva internacional, o deslocamento das indústrias nacionais para países em desenvolvimento e o crescimento do setor terciário no país - levou a ênfase e investimento nacional nas indústrias do conhecimento, tais como tecnologia de software, mídias, educação, bem-estar, artes visuais, música, entretenimento, hospitalidade, lazer e outras atividades culturais.

Os conflitos sobre as formas de representação das "japonesidades" nos meios de comunicação de massa brasileiros entre 2016 e 2017 envolveram tanto as imagens de uma família japonesa em Sol Nascente (2016/2017) quanto as imagens dos otakus e cosplayers em A Força do Querer (2017), ambas são telenovelas da Rede Globo. Em 2016, a chamada de uma telenovela brasileira trazia a história de amizade entre duas famílias de imigrantes, uma japonesa e uma italiana. Antes mesmo de sua estreia, surgiram críticas em relação à composição do elenco, visto que o personagem Tanaka, um mestiço de descendência japonesa e norte-americana, seria representado pelo ator Luís Melo, que não possui essa corporalidade. Em relação às críticas pela escolha do ator, o autor da novela apresentou como justificativa não ter encontrado um "bom ator japonês". ${ }^{12}$ Esse conflito deu impulso a uma série de discussões sobre a "yellow face", as práticas de branqueamento de personagens e a reprodução de estereótipos. No ano seguinte, diversos cosplayers e otakus se manifestaram contra a representação estereotipada do personagem Yuri em A Força do Querer..$^{13} \mathrm{O}$ personagem em questão foi apresentado como um

12 MENGUE, P. Além do "Sol Nascente": artistas nipônicos reivindicam representatividade na TV e no cinema. O Estado de São Paulo, São Paulo, 02 set. 2016. Disponível em: https://emais.estadao.com.br/noticias/tv,alem-de-sol-nascente-artistas-niponicos-reivindicam-representatividade-na-tv-e-no-cinema, 10000073773. Acesso em: 29 jul. 2019.

13 COSPLAYERS criticam personagem de 'A Força do Querer'; Globo diz que respeita diversidade. Estadão, São Paulo, 04 abr. 2017. Disponível em: https://emais.estadao.com.br/noticias/tv,cosplayers-criticam-persona- 
adolescente que se veste cotidianamente com cosplay, fala palavras japonesas e preocupa os pais por seu vício em tecnologia e dificuldades de socialização. ${ }^{14}$

Através da hashtag \#yurinaomerepresenta, ${ }^{15}$ diversos cosplayers se posicionaram contra a imagem estereotipada do personagem. A comunidade Cospositivismo, formada por "iniciativa de união e inclusão entre cosplayers, uma página de divulgação de cosplayers engajada em mostrar a diversidade existente no universo cosplay" (COSPLAYERS..., 2017) afirma que:

Cosplayers são pessoas normais, mães e pais, homens e mulheres de diversas idades, de várias etnias e tipos físicos diferentes. Pessoas que também acordam cedo pra trabalhar e chegam tarde cansadas do trabalho, aliás, trabalho que nos dá dinheiro e recursos para correr atrás de nossa paixão por essa arte. Muitos de nós ganhamos a vida fazendo esta arte para poder pagar as despesas no fim do mês. (COSPLAYERS..., 2017, on-line).

No período entre 2016 e 2017 também surgiram diversos coletivos formados por descendentes de asiáticos no Brasil. O Coletivo Oriente-se ${ }^{16}$ (2016, on-line) pontua que "há pouca representatividade de nossa etnia nas produções culturais cênicas" e, em geral, os atores asiáticos são escalados para papéis que reforçam imagens equivocadas e não representam a realidade desse grupo étnico. O canal no YouTube, Yo Ban $\mathrm{Boo}^{17}$, era um projeto de um cineasta e dois atores que se reuniram para produzir vídeos humorísticos com foco nas experiências dos descendentes de asiáticos no Brasil. Entre alguns dos vídeos com maior visibilidade estão o humorístico sobre "Coisas que os asiáticos brasileiros sempre ouvem" (14 jul. 2016) e o "A participação asiática no racismo anti-negro" (07 mar. 2017), baseado no texto do blog Outra Coluna ${ }^{18}$.

O Outra Coluna é um coletivo iniciado por descendentes de asiáticos formados em áreas como Ciências Sociais, Direito, Relações Internacionais, Língua e cultura japonesa. A página de apresentação do coletivo possui três fotografias publicadas pela revista Life. Na pri-

gem-de-a-forca-do-querer-globo-diz-que-respeita-diversidade,70001725935. Acesso em: 29 jul. 2019.

14 Katekawa (2016) observa a transformação na imagem do otaku no Japão, de problema social nos anos 80 à solução política e econômica nos anos 2000 , e as mudanças culturais, políticas e econômicas que influenciaram essa transformação.

15 Disponível em: https:/pt-br.facebook.com/CosPositivismo/posts/1877732025782394/. Acesso em: 29 jul. 2019.

16 Disponível em: http://www.orientese.com.br/quem-somos. Acesso em: 12 jun. 2019.

17 Disponível em: https://www.youtube.com/channel/UCmPMXwu814q81DOd_OTx26Q. Acesso em: 12 jun. 2019.

18 Disponível em: https://outracoluna.wordpress.com/. Acesso em: 12 jun. 2019. 
meira fotografia, com a cabeça apoiada nas mãos de uma mulher de aparência asiática, está o corpo de um homem negro baleado no chão, enquanto as suas vestes são abertas por outra pessoa. Na segunda fotografia, um rapaz aproxima o seu rosto do homem como quem confere a respiração e, na terceira fotografia, pessoas ao redor como em um lamento. Através dessas imagens, observa-se a proximidade da mulher presente na primeira foto, Yuri Kochiyama, com as reuniões da Organização da Unidade Afro-Americana e a sua militância pelos direitos da classe trabalhadora e das minorias não brancas. A proximidade entre Kochiyama e Malcom X, estaria nos "elos de solidariedade contra os avanços do imperialismo e os desdobramentos do colonialismo" (ANDÓ FILHO, 2015, on-line). A partir do legado de Kochiyama, os membros do coletivo apontam para:

[...] a construção de solidariedade entre as minorias não brancas na luta contra o racismo e o patriarcado. Por sua vez, entendemos o racismo como um sistema que define a superioridade de uma raça sobre as outras, por meio de uma estrutura de crenças, comportamentos, usos da linguagem e políticas. [...] Os discursos de dominação racial, que mantêm e reproduzem a ideia de supremacia branca, foram essenciais para legitimar as investidas imperialistas dos estados modernos ocidentais e os modelos de exploração colonial e neocolonial. Para além do que parece só história, a opressão sobre minorias não brancas ainda opera sob a mesma lógica de dominação, agindo a favor do controle das classes trabalhadoras; na promoção do ódio racial internalizado e entre grupos identitários; no controle da sexualidade da população não branca; na repressão da população LGBT; no genocídio da juventude negra e periférica; na construção ideológica de uma hierarquia de saberes; no racismo institucional, tudo em prol da manutenção de privilégios de um mundo de brancos feito para brancos. (ANDÓ FILHO, 2015, on-line) ${ }^{19}$.

Um movimento semelhante também pode ser observado no Coletivo Asiáticos pela Liberdade $^{20}$ e na Plataforma Lótus ${ }^{21}$, que organizam eventos regulares para estimular o debate sobre raça, gênero, sexualidade, classe e etnia. Entre 2016 e 2018, através da ação desses coletivos, surgiram diversas reportagens, tais como "Anti-negritude é global: a participação asiática no racismo anti-negro" (ANTI-NEGRITUDE..., 2016), "O mito da minoria modelo" (SAYURI, 2017) e "Feminismo nikkei: a luta das descendentes de asiáticos contra estereótipos" (TAKASHIMA, 2018), que trouxeram questões sobre a migração asiática no Brasil, os seus contextos históricos e as mudanças culturais contemporâneas. Através do compartilhamento

19 Disponível em: https://outracoluna.wordpress.com/apresentacao/. Acesso em: 25 set. 2019.

20 Disponível em: https://pt-br.facebook.com/asiaticosdiversidade/. Acesso em: 25 set. 2019.

21 Disponível em: https://pt-br.facebook.com/plataformalotus/. Acesso em: 25 set. 2019. 
de histórias de ascendentes e de experiências pessoais de descendentes no Brasil, essas reportagens chamam a atenção para a história da migração japonesa no Brasil e o mito da minoria modelo (PETTERSEN, 1966; WU, 2014) construída nos anos 60, que transformava a figura do "perigo amarelo" em uma imagem dócil e focada. Observam através das experiências de mulheres mestiças de descendência asiática no Brasil atual, o fetichismo em torno da mulher asiática e a sua ligação histórica com as incursões militares norte-americanas no Japão, China e Vietnã, e a exploração sexual ocorrida neste contexto de dupla dominação.

Considerar a diversidade de misturas possíveis da cultura japonesa no Brasil, observando os corpos como mediadores nas práticas culturais incorporadas nos leva a perceber as particularidades da mestiçagem, do hibridismo e da transculturação. Como pontua Taylor (2013), as noções de mestiçagem, hibridismo e transculturação diferem, pois suas relações com a incorporação realçam facetas diferentes da história colonial . A mestiçagem como conceito de fusão biológica e/ou cultural utilizada na América Latina "tem uma história”, “conta uma história" e "incorpora uma história", tomando o corpo numa perspectiva biológica. Apesar da centralidade no corpo na ideia de mistura biológica, os termos mestiço e mestiçagem não podem ser reduzidos aos contornos do corpo, visto que "[...] a subjetividade negociada do/a mestiço/a evidencia alianças que vão muito além dos traços raciais, e as ramificações políticas do conceito de mestiçagem moldam as histórias culturais latino-americanas" (TAYLOR, 2013, p. 145).

Tal como a mestiza de Anzaldúa (1987), a Intermediária - personagem da peça teatral de Carballido (1965) - também sente no corpo o "nódulo de convergência que une o individual ao coletivo, o privado ao social, o diacrônico ao sincrônico, a memória ao conhecimento" (TAYLOR, 2013, p.127). Ela revela os contextos de seu início e as transcende, encenando uma história por meio da incorporação racializada. Nesse processo, conexões entre conhecimento incorporado, memória e história nos auxiliam a entender que as "[...] misturas raciais e culturais tão entranhadas nos imaginários sociais latino-americanos, carregam também histórias de transmissão." (TAYLOR, 2013, p. 143).

A noção de hibridismo, dominante nos estudos pós-coloniais oriundos da Índia e da diáspora africana, conota um processo de categorização social. A colonização indiana se desenvolveu como um empreendimento comercial e não como produção de "uma nova raça". Taylor (2013) observa que tanto Spivak quanto Bhabha falam do hibridismo como um efeito do poder colonial e que a "duplicidade" não se refere às pessoas, mas aos espaços e aos sistemas de poder. Com isso, Taylor (2013) não coloca uma hierarquização sobre as diferenças, mas aponta para os diferentes modos de incorporação nessas relações. Apesar das diferenças, “[...] ambas as teorias elucidam nosso presente e não são nem mutuamente exclusivas nem idênticas - elas 
nos dizem coisas diferentes sobre nosso presente colonial heterogêneo e composto de muitas camadas" (TAYLOR, 2013, p.157).

A questão e os debates sobre as misturas também tangenciam a noção de transculturação (ORTIZ, 1987; RAMA, 1982). Pensada como troca recíproca, por meio do contato, essa perspectiva considera a seletividade e a inventividade que existe na transculturação. Ianni (1996, p. 153) observa que a noção de transculturação "proporciona um termo que não contém a implicação de uma dada cultura à qual deve ter a outra, mas uma transição entre duas culturas, ambas ativas, ambas contribuintes e ambas cooperantes para o advento de uma nova realidade civilizatória".

A globalização e as produções das localidades na contemporaneidade tem sido o foco de questionamento de diversos autores (APPADURAI, 2004; STRATHERN, 2004; AUGÉ, 1994; GIDDENS, 2002; HANNERZ, 1992). O intenso deslocamento de pessoas, artefatos, palavras e imagens com as quais nos conectamos cotidianamente nos mostram as instabilidades na moderna produção de subjetividades e de conhecimentos. Justapostos, migrações e meios de comunicação de massa têm um efeito conjunto sobre a obra da imaginação (APPADURAI, 2004). Imaginação que se desloca do característico espaço da arte, do mito e do ritual para as experiências cotidianas. Entretanto, com o constante trânsito de pessoas, imagens, informações, artefatos e ideias, somos confrontados com os limites das categorias conceituais e organizacionais que estamos habituados, ao mesmo tempo que tomamos consciência das posições relacionais dos sujeitos (BHABHA, 2007). A ruptura das fronteiras trouxe o questionamento da concepção de sujeito, assim como a busca de subjetividades originárias da cultura que permearam as teorias. Ao transpor tal noção e focalizar nos processos em que as diferenças culturais são articuladas, podemos observar que são nos interstícios que as experiências, os interesses e o valor são negociados.

Através da crítica às concepções epistemológicas dominantes nos estudos culturais e utilizando como método a desconstrução dos essencialismos, os estudos pós-coloniais apontam os obstáculos de resumir, ontologicamente, o mundo a elementos que compõem um todo e, ao mesmo tempo, estabelecer uma relação epistemológica em que esses componentes se formam na capacidade de conhecer os estado das coisas de uma maneira propositiva-racional, pautada no uso de sentenças assertivas, e utilizando como objetividade um referencial que se configura através da relação entre diferenças.

Como observa Bhabha (2007, p. 330-331), tal questão poderia ser figurativamente descrita como "[...] uma preocupação não simplesmente com o reflexo no vidro - a ideia ou conceito em si - mas com os enquadramentos do sentido do modo como são revelados no que 
Derrida chamou de necessidade suplementar de um parergon" (BHABHA, 2007, p. 330-331). Ou seja, levar em consideração, nos discursos sobre e da verdade, o caráter ambivalente de estar “dentro e fora”. Costa (2006) analisava as contribuições dos estudos pós-coloniais por meio da apresentação de alternativas epistemológicas que introduzem a busca por lugares híbridos de enunciação, ao mesmo tempo que criticam o modernismo como teleologia da história e a concepção de sujeito, base das Ciências Sociais.

A partir da segunda metade do século XX, nota-se um intenso processo de deslocamento da concepção do sujeito moderno, através dos debates marxistas da década de 60 , da exploração do inconsciente por Freud e Lacan, a questão da linguagem em Saussure e Derrida, o poder disciplinar em Foucault, e a crítica teórica e movimento social deflagrado pelo feminismo. $\mathrm{Na}$ década de 70, e com mais força na de 80, vemos surgir os estudos pós-coloniais. Sem uma matriz teórica única e utilizando como método a desconstrução dos essencialismos, os teóricos da diáspora (como foram chamados os autores desses estudos) traziam uma referência epistemológica crítica em relação às concepções teóricas dominantes. Sendo produzidos em sua maioria, por intelectuais imigrantes oriundos de países pobres que vivem na Europa Ocidental e América do Norte, os estudos pontuam (com base na compreensão de que toda enunciação vem de algum lugar) que, ao privilegiar modelos explicativos e conteúdos próprios ao que se definiu como a cultura nacional nos países europeus, o processo de produção do conhecimento científico acaba por reproduzir a lógica da relação colonial (COSTA, 2006).

O orientalismo, termo cunhado por Said (1990), enfoca a percepção de um olhar que se repete e que:

[...] caracteriza uma maneira particular de percepção da história moderna e tem como ponto de partida o estabelecimento a priori de uma distinção binária entre Ocidente e Oriente, segundo a qual cabe àquela parte que se autorepresenta como Ocidente a tarefa de definir o que se entende por Oriente. O orientalismo constitui, assim, uma maneira de apreender o mundo, ao mesmo tempo que se consolida, historicamente, a partir da produção de conhecimentos pautados por aquela distinção binária original. (COSTA, 2006, p. 118-119)

\section{CONSIDERAÇÕES FINAIS}

É através da experiência de deslocamento que somos obrigados a repensar nossas categorias convencionalizadas de viver e identificar novas potencialidade e possibilidades. 
Neste processo, a cultura em que crescemos torna-se visível, deixando de ser percebida como "dada e autoevidente". Nesse ato de inventarmos outra cultura, acabamos por inventar e reinventar a nossa própria noção de cultura (WAGNER, 2010). Entre invenções e convenções, nos deparamos com o questionamento dos termos utilizados nas análises. Viveiros de Castro (2002) afirma que tanto o discurso do antropólogo quanto o discurso do nativo não deveriam ser vistos como "textos", mas sim como práticas de sentido. Ao partirmos da pressuposição de que a cultura do nativo é expressa de modo "natural", enquanto a cultura do antropólogo é expressa "culturalmente" de modo reflexivo, condicional e consciente, somos levados a uma concepção ambígua de cultura em que, por um lado, há um que usa a cultura, e por outro, um que é usado por ela. A diferença entre essas culturas não está na sua natureza, mas sim no jogo de linguagem em que antropólogo e nativo são descritos. A questão é que nesse jogo de linguagem, apesar da ideia de cultura colocar antropólogo e nativo em um mesmo patamar de "igualdade", observa-se que essa igualdade se apresenta apenas em relação a uma condição cultural comum e não no plano do conhecimento.

Strathern (2013) diz que o foco ainda deve ser o de falar das práticas de conhecimento daqueles a que nos propomos estudar, sem deixar de lado o choque cultural e a mediação do pesquisador que, ao transitar entre diferentes contextos, proporciona de forma inventiva a produção de conhecimento. A necessidade de simetrizar, não no sentido de eliminar as diferenças, mas sim compreender e assumir a existência das diferenças sem perder de vista as forças e as relações de poder em que os discursos se constroem, nos permite buscar parear os poderes através da percepção de que os espaços de diálogo e produção do conhecimento tendem a pesar as falas de acordo com regras e critérios específicos de cada meio.

\section{REFERÊNCIAS}

1. ANTI-NEGRITUDE é global: a participação asiática no racismo anti-negro. Outra Coluna, 13 jun. 2016. Disponível em: https://outracoluna.wordpress.com/2016/06/13/ a-participacao-asiatica-no-racismo-anti-negro/?wref=tp. Acesso em: 23 maio 2019.

2. ANZALDÚA, G. Bordelands/la frontera: the new mestiza. San Francisco: Spinsters/ Aunt Lute, 1987.

3. APPADURAI, A. Aqui e agora. In: APPADURAI, A. Dimensões culturais da globalização. Tradução Telma Costa. Portugal: Editorial Teorema, 2004, p. 11-40. 
4. AUGÉ, M. Não-lugares: introdução a uma antropologia da supermodernidade. Tradução de Maria Lúcia Pereira, Campinas: Papirus, 1994.

5. BHABHA, H. O local da cultura. Tradução Myriam Ávila, Eliana Lourenço de Lima Reis e Gláucia Renate Gonçalves. Belo Horizonte: UFMG, 2007.

6. CARLSON, M. Performance: uma introdução crítica. Tradução Thais Flores Nogueira Diniz e Maria Antonieta Pereira. Belo Horizonte: Editora UFMG, 2010.

7. COSPLAYERS criticam personagem de 'A Força do Querer'; Globo diz que respeita diversidade. Estadão, São Paulo, 04 abr. 2017. Disponível em: https://emais.estadao. com.br/noticias/tv,cosplayers-criticam-personagem-de-a-forca-do-querer-globo-dizque-respeita-diversidade, 70001725935. Acesso em: 29 jul. 2019.

8. COSTA, S. Desprovincializando a sociologia: a contribuição pós-colonial. Revista Brasileira de Ciências Sociais, São Paulo, v.21, n. 60, p.117-134, 2006.

9. CARBALLIDO, E. Yo también hablo de la rosa. México, 1965.

10. COTRIM, A. S. Imigração japonesa no Peru e no Brasil: motivações, dificuldades e assimilação. In: SIMPÓSIO INTERNACIONAL PENSAR E REPENSARAAMÉRICA LATINA, 2., 2016, São Paulo. Anais... São Paulo: Escola de Comunicação e Artes da Universidade de São Paulo, 2016.

11. DAWSEY, J. Turner, Benjamin e Antropologia da Performance: o lugar olhado (e ouvido) das coisas. Campos, Curitiba, v. 7, n.2, p. 17-25, 2006.

12. ANDÓ FILHO, F. Apresentação do Outra Coluna, Outra Coluna 16 dez. 2015. Disponível em: https://outracoluna.wordpress.com/apresentacao/. Acesso em: 23 maio 2019.

13. FOUCAULT, M. Vigiar e punir: nascimento da prisão. Tradução de Raquel Ramalhete. Petrópolis: Vozes, 1987.

14. GIDDENS, A. Modernidade e identidade. Tradução de Plínio Dentzien. Rio de Janeiro: Jorge Zahar Ed., 2002.

15. HANNERZ, U. Cultural Complexity. New York: Columbia University Press, 1992.

16. HATUGAI, E. R. A medida das coisas: japonesidades e parentesco entre associados da Nipo em Araraquara. 2011. 150 f. Dissertação (Mestrado em Ciências Humanas) - Universidade Federal de São Carlos, São Carlos, 2011. Disponível em: https:// repositorio.ufscar.br/handle/ufscar/204?show=full. Acesso em: 09 jan. 2020.

17. HATUGAI, E. R. O lugar do "mestiço" na história da imigração japonesa. Corpo, conflito e parentesco entre famílias interétnicas. In: ENCONTRO ANUAL DA ANPOCS, 39., 2015, Caxambu. Anais... Caxambu: ANPOCS, 2015. p. 1-27. Disponível em: https:// anpocs.com/index.php/encontros/papers/39-encontro-anual-da-anpocs/spg/spg08. Acesso em: 10 jan. 2020. 
18. IANNI, O. Globalização e transculturação. Revista de Ciências humanas, Florianópolis, v.14, n.20, p.139-170, 1996. Disponível em: https://periodicos.ufsc.br/index.php/ revistacfh/article/view/23492/21159. Acesso em 25 set 2019.

19. KATEKAWA, H. E. O fenômeno otaku: de problema social à solução política. 2016. 90 f. Dissertação (Mestrado em Cultura Japonesa) - Faculdade de Filosofia, Letras e Ciências Humanas, São Paulo, 2016. Disponível em: https://teses.usp.br/teses/ disponiveis/8/8157/tde-13032017-110556/publico/2016_HenriqueEidinKatekawa_ VOrig.pdf. Acesso em: 19 jun. 2019.

20. LESSER, J. O hífen oculto. In: LESSER, J. A Negociação da Identidade Nacional: imigrantes, minorias e a luta pela etnicidade no Brasil. Tradução Patrícia de Queiros Carvalho Zimbres. São Paulo: Editora UNESP, 2001. p. 17-36.

21. LINGER, D. T. No One Home: Brazilian Self Remade in Japan. Stanford: Stanford University Press, 2001.

22. LOURENÇÃO, G. V. Identidades, práticas e moralidades transnacionais: etnografia da esgrima japonesa no Brasil. 2009. 367 f. Dissertação (Mestrado em Antropologia Social) - Universidade Federal de São Carlos, São Carlos, 2009. Disponível em: https:// repositorio.ufscar.br/bitstream/handle/ufscar/192/2772.pdf?sequence=1. Acesso em: 11 jan 2020.

23. MACHADO, I. J. R. Japonesidades multiplicadas: novos estudos sobre a presença japonesa no Brasil. São Carlos: EdUFScar, 2011a.

24. MACHADO, I. J. R. Japonesidades Múltiplas: migração desalinhada. In: REUNIÃO DE ANTROPOLOGIA DO MERCOSUL, 9., 2011b, Curitiba. Anais... Curitiba: UFPR, 2011. Disponível em: https://www.servidores.ufscar.brigor/wp-content/uploads/ra.pdf. Acesso em: 11 jan. 2020.

25. MATSUE, R. Y.; PEREIRA, P. P. G. Quem se diferencia apanha (deru kui há watareru): experiência etnográfica, afeto e antropologia no Japão. Mana, Rio de Janeiro, v. 23, n.2, p. 427-454, 2017.

26. MAUSS, M. Sociologia e antropologia. Tradução de Paulo Neves, Cosac Naify, São Paulo, 2003.

27. MORI, L. Os descendentes que preservaram no Brasil uma língua que quase não se fala mais no Japão. BBC Brasil, São Paulo, 22 jan. 2018. Disponível em: https://www.bbc. com/portuguese/brasil-42775209. Acesso em: 02 fev. 2018.

28. NAGAMI, I. C. Antropologia da performance: a experiência do cosplay e as ações performáticas. In: SEMINÁRIO DE PESQUISA EM CIÊNCIAS HUMANAS, 8., 2010, Londrina. Anais... Londrina: Centro de Letras e Ciências Humanas, Universidade Estadual de Londrina, 2010. p. 956-969. Disponível em: http://www.uel.br/eventos/ sepech/sumarios/temas/antropologia_da_performance_a_experiencia_do_cosplay_e_ as_acoes_performaticas.pdf. Acesso em: 22 ago. 2019. 
29. NAGAMI, I. C. Entre contadores de histórias, cosplayers e ciborgues: sobre as narrativas, as imagens e os híbridos na cibercultura. 2016. 105 f. Dissertação (Mestrado em Ciências Sociais) - Universidade Estadual de Londrina, Londrina, 2016. Disponível em: http://www.bibliotecadigital.uel.br/document/?code=vtls000205332. Acesso em: 22 ago. 2020.

30. NAKAMOTO, A. L. C. Representações do feminino na imigração japonesa e okinawana. 2019. 225 f. Tese (Doutorado em Sociologia) - Universidade de São Paulo, São Paulo, 2019. Disponível em: https://www.teses.usp.br/teses/disponiveis/8/8132/tde-22082019114415/publico/2019_AnaLuisaCampanhaNakamoto_VCorr.pdf. Acesso em: 09 jan. 2020.

31. OLIVEIRA, H. A.; MASIERO, G. Estudos Asiáticos no Brasil: contexto e desafios. Revista Brasileira de Política Internacional, Brasília, v. 48, n. 2, p. 5-28, 2005.

32. ORTIZ, F. Contrapunteo cubano del tabaco y el azúcar. Caracas: Biblioteca Ayacucho, 1987.

33. PEIRANO, M. Etnografia não é método. Horizontes Antropológicos, Porto Alegre, ano 20, n. 42, p. 377-391, 2014. Disponível em: http://www.scielo.br/pdf/ha/v20n42/15. pdf. Acesso em: 11 ago. 2019.

34. PEREIRA, R. A. Estudos asiáticos no Brasil. In: GUIMARÃES, Lytton L. (org.). Ásia, América Latina, Brasil: a construção de parcerias. Brasília: NEASIA; CEAM; UnB, 2003. p.105-124. Disponível em: repositorio.unb.br/bitstream/10482/1591/1/ CAPÍTULO_EstudosAsiaticosBrasil.pdf. Acesso em: 26 ago. 2019.

35. PETTERSEN, W. Sucess story, Japanese-American style, New York Times, New York, 9 jan. 1966. Disponível em: http://inside.sfuhs.org/dept/history/US_History_reader/ Chapter14/modelminority.pdf. Acesso em: 01 jun. 2019.

36. RAMA, A. Transculturación narrativa en América Latina. Montevideo: Fundación Ángel, 1982.

37. RONCATO, M. S. Trabalho imigrante dekassegui: classe social, etnia e gênero. In: ANTUNES, Ricardo. (org.). Riqueza e miséria do trabalho no Brasil. v. 4, São Paulo: Boitempo, p.101-120, 2019.

38. SAID, E. W. Orientalismo: o Oriente como invenção do Ocidente. Tradução Tomás Rosa Bueno, São Paulo, Companhia das Letras, 1990.

39. SAITO, H. A imigração e os problemas de população no Japão. O Observador Econômico e Financeiro, ano XIII, n. 272, p. 14-22, 1958.

40. SAITO, H.; MAEYAMA, T. Assimilação e integração dos japoneses no Brasil. Petrópolis: Vozes, 1973.

41. SAKURAI, C. Imigração tutelada, os japoneses no Brasil. 2000. $191 \mathrm{f}$. Tese (Doutorado em Antropologia) - Universidade Estadual de Campinas, Campinas, 2000. 
Disponível em: http://repositorio.unicamp.br/jspui/handle/REPOSIP/280717. Acesso em: 10 set 2019.

42. SATO, C. A. Kimono. Cultura Japonesa, 30 ago. 2007. Disponível em: http://www. culturajaponesa.com.br/index.php/diversos/kimono/. Acesso em: 13 jan. 2020.

43. SAYURI, J. O mito da minoria modelo ou porque precisamos discutir discriminação contra asiáticos. Vice, 7 fev. 2017. Disponível em: https://www.vice.com/pt/ article/787gka/o-mito-da-minoria-modelo. Acesso em: 23 maio 2019.

44. SILVA, V. H. K. Um Jornal entre Brasil e Japão: a construção de uma identidade para 'japoneses no Brasil' e 'brasileiros no Japão”. 2008. 171 f. Dissertação (Mestrado em Ciências Sociais) - Universidade Federal de São Carlos, 2008. Disponível em: https:// repositorio.ufscar.br/handle/ufscar/1466. Acesso em: 11 jan. 2020

45. STRATHERN, M. Fora de contexto: as ficções persuasivas da antropologia. São Paulo: Terceiro Nome, 2013.

46. STRATHERN, M. Partial Connections, Updated Edition. Walnut Creek: Altamira Press, 2004.

47. SUGIMOTO, Y. Japanese Society: Inside out and Outside in. International Sociology, v. 29, p.191-208, abr./maio, 2014. Disponível em: https://journals.sagepub.com/ doi/10.1177/0268580914530416?icid=int.sj-abstract.similar-articles.1. Acesso em: 07 set. 2019.

48. SUGIMOTO, Y. Making Sense of Nihonjinron. Thesis Eleven. v. 57, maio, p. 81-96, 1999. Disponível em: https://journals.sagepub.com/doi/10.1177/072551369905700000 7. Acesso em: 15 set. 2019.

49. TAKASHIMA, A. Feminismo nikkei: a luta das descendentes de asiáticos contra estereótipos. Revista Marie Claire, 28 jul. 2018. Disponível em: https:// revistamarieclaire.globo.com/Noticias/noticia/2018/07/feminismo-nikkei-luta-dasdescendentes-de-asiaticos-contra-estereotipos.html. Acesso em: 23 maio 2019.

50. TAKEUCHI, M. Y. O perigo amarelo no Brasil dos anos 40: construindo a imagem do japonês indesejável. In: SIMPÓSIO NACIONAL DE HISTÓRIA, 22., 2003, João Pessoa. Anais... João Pessoa: ANPUH. Disponível em: https://anpuh.org.br/uploads/ anais-simposios/pdf/2019-01/1548177543_f645546be081dd883ec4307115311116.pdf. Acesso em: 19 out. 2019.

51. TAYLOR, D. O arquivo e o repertório: performance e memória cultural nas Américas. Tradução Eliana Lourenço de Lima Reis. Belo Horizonte: Editora UFMG, 2013.

52. TSUDA, T. Strangers in the homeland: Japanese brazilian return migration in transnational perspective. New York: Columbia University Press, 2003.

53. TURNER, V. Liminal ao liminoide: em brincadeira, fluxo e ritual; um ensaio de simbologia comparativa. Tradução Herbert Rodrigues e Evelise Paulis. Mediações, 
Londrina, v. 17 n. 2, p. 214-257, 2012. Disponível em: http://www.uel.br/revistas/uel/ index.php/mediacoes/article/view/14343/11951. Acesso em: 22 nov. 2013.

54. VAN GENNEP, A. The Rites of Passage. London: Routledge and Kegan Paul, 1960.

55. VIVEIROS DE CASTRO, E. O nativo relativo. Mana, Rio de Janeiro, v. 8, n. 1, p. 113-148, 2002.

56. WAGNER, R. A invenção de cultura. São Paulo: Cosac Naify, 2010.

57. WU, E. D. The color of success: asian americans and the origin of the model minority, New Jersey: Princeton University Press, 2014.

Isis Caroline Nagami

Doutoranda em Ciências Sociais na Universidade Estadual Paulista Júlio de Mesquita Filho. Mestrado (2016) e Graduação (2011) em Ciências Sociais pela Universidade Estadual de Londrina. Editora na Cadernos de Campo: Revista de Ciências Sociais e membro do Núcleo de Antropologia da Imagem e Performance. ID ORCID: http://orcid.org/0000-0001-9450-5744. E-mail: isisnagami@unesp.br. 